Audit Quality Factors Which Moderated Time Budget Pressure (Survey In Accounting Public Firm Jateng DIY)

\title{
Faktor-Faktor Kualitas Hasil Audit Yang Dimoderasi Time Budget Pressure (Survey KAP di Jateng DIY)
}

\author{
Dewi Saptantinah PA ${ }^{1}$, Aris Eddy Sarwono ${ }^{2}$ \\ 1,2) Prodi Akuntansi Fakultas Ekonomi Universitas Slamet Riyadi Surakarta \\ E-mail: dewi.astutie@gmail.com ${ }^{1}$; aris_sarnur@yahoo.co.id ${ }^{2}$
}

\begin{abstract}
This study aims to determine several factors that influence the quality of audit results which are moderated by time budget pressure. The factors used as independent variables are audit fees and audit experience, the dependent variable is the quality of audit results, while time budget pressure is a moderating variable. Respondents in this study were auditors at the Public Accountant Firm (KAP) in Central Java and Yogyakarta by taking samples using accidental sampling. The results of this study state that audit fees and audit experience have a significant effect on the quality of audit results, then time budget pressure also moderates the effect of audit fees and audit experience on the quality of audit results. Suggestions for further research should be to broaden KAP research objects throughout Indonesia or by comparing Big 4 and Non Big 4 KAPs so that research results can be generalized more.
\end{abstract}

Keywords: Audit Fee, Audit Experience, Time Budget Pressure and Quality of Audit Results

Abstrak

Penelitian ini bertujuan untuk mengetahui beberapa faktor yang mempengaruhi kualitas hasil audit yang dimoderasi oleh time budget pressure. Faktor-faktor yang digunakan sebagai variabel independen adalah fee audit dan pengalaman audit, variabel dependennya adalah kualitas hasil audit, sedangkan time budget pressure sebagai variabel moderasi. Responden dalam penelitian ini adalah auditor pada Kantor Akuntan Publik (KAP) di Jawa Tengah dan DIY dengan pengambilan sampel menggunakan accidental sampling. Hasil penelitian ini menyatakan bahwa fee audit dan pengalaman audit berpengaruh signifikan terhadap kualitas hasil audit, kemudian time budget pressure juga memoderasi pengaruh antara fee audit dan pengalaman audit terhadap kualitas hasil audit. Saran bagi penelitian selanjutnya hendaknya memperluas obyek penelitian KAP se Indonesia atau dengan membandingkan KAP Big 4 dan Non Big 4 sehingga hasil penelitian lebih dapat digeneralisasi.

Kata kunci: Fee Audit, Pengalaman Audit ,Time Budget Pressure dan Kualitas Hasil Audit

\section{PENDAHULUAN}

Akuntan publik merupakan suatu profesi yang dipercaya ,sebagai pihak yang independen dalam menilai kewajaran kondisi keuangan perusahaan. Pihak yang melaksanakan tersebut adalah auditor yang dalam pelaksaan audit berpedoman Standar Profesionalisme Akuntan Publik, yang mencakup standar umum, standar pekerjaan lapangan dan standar pelaporan. Fenomena dari kasus ini adalah audit yang dilaksanakan di PT Garuda Indonesia, yang dalam hal ini auditor dari Kantor Akuntan Publik yang bersangkutan dibekukan ijinnya karena hasil audit yang tidak berkualitas karena memberikan opini yang tidak semestinya, dan Kantor Akuntan Publik belum menerapkan system pengendalian mutu (www,cnnindonesia.com, 2019).

Beberapa faktor yang mempengaruhi kualitas audit, diantaranya fee audit, tingkat pengalaman audit, etika profesi, kompetensi,keahlian profesional dan masih banyak faktor yang mempengaruhi kualitas audit. Fee Audit memiliki arti imbalan yang akan diterima auditor setelah melaksanakan jasa audit. Besarnya fee yang akan diterima berpengaruh pada kualitas audit. Karena hal tersebut, penentuan fee harus disepakati antara klien dengan auditor, agar tidak terjadi beda tarif yang bisa merusak kredibilitas auditor. Hal tersebut didukung dengan hasil penelitian yang dilakukan oleh Kamil dkk (2018), Chrisdinawidanty dkk (2016), Andriani dan Nursiam (2017), penelitian luar negeri adalah Mulyani dan Munthe (2018), dan Abdul Rahman dkk (2017) yang meneliti di Nigeria menyimpulkan bahwa audit fee memiliki pengaruh yang signifikan dan positif terhadap kualitas audit. 
Sedangkan penelitian luar negeri yang berlawanan oleh Kam Wah Lai (2019) yang meneliti perusahaan merger KAP di Hongkong, yaitu antara Deloitte and Kwan hasilnya menyatakan bahwa setelah merger KAP Deloitte terlihat tidak membebankan fee audit yang tinggi dan juga tidak terlihat penurunan kualitas audit, artinya kualitas audit tidak berpengaruh secara langsung dengan kualitas auditmya,disamping itu juga dalam penelitian ini meneliti variabel lain yaitu audit report lag, hasilnya juga menyatakan bahwa KAP yang bersansgkutan juga tidak menunjukkan keterlambatan penyampaian audit (audit report lag).

Faktor selanjutnya yang berpengaruh terhadap kualitas audit adalah pengalaman audit. Pengalaman auditor tersebut akan memberikan dampak di setiap keputusan yang diambil dalam melaksanakan tugas sehingga diharapkan keputusan yang diambil adalah keputusan yang tepat (Kamil dkk, 2018). Pengalaman auditor bisa didapat dari pelatihan, supervisi, dan juga review terhadap hasil kerjanya yang diberikan oleh senior yang lebih berpengalaman. Penelitian ini berasumsi bahwa semakin auditor berpengalaman maka kualitas audit semakin meningkat. Murat dan Ocak (2019) yang meneliti tentang pengaruh auditor pemerintah yang berpengalaman terhadap kualitas audit di Bursa Istambul menghasilkan penelitian yang berlawanan, bahwa semakin auditor tersebut berpengalaman justru membuat kualitas audit mereka menurun.

Adapun faktor lain yang mempengaruhi kualitas audit adalah Time Budget Pressure. Robertus Aryo Kusumo (2016) yang meneliti pengaruh time budget pressure terhadap kualitas audit menyatakan tidak ada pengaruh time budget pressure terhadap kualitas audit. Penelitian Valentina (2013) menyatakan time budget pressure tidak berpengaruh terhadap kualitas audit. Sedangkan Putu Dian Indah (2018) menggunakan Time Budget Pressure sebagai variabel yang memoderasi antara Due Professional Care dan Pengalaman Audit Terhadap Kualitas Audit, hasilnya variabel time budget pressure dapat memperkuat hubungan variabel due professional care dan variabel kualitas audit, sedangkan variabel time budget pressure memperlemah suatu hubungan antara variabel pengalaman audit dengan variabel kualitas audit. Svanberg dan Ohman (2013) meneliti tentang pengaruh variabel time budget pressure terhadap kualitas audit yang di mediasi oleh budaya etis, hasil penelitian menunjukkan bahwa budaya etis yang berperan sebagai variabel mediasi dapat memediasi pengaruh antara time budget pressure dengan kualitas audit.

Penelitian yang dilakukan saat ini mengacu pada penelitian yang dilakukan oleh Putu Dian Indah Savitri (2018) yang meneliti Moderasi antara Time Budget Pressure dengan Due Professional Care dan Pengalaman Audit Terhadap Kualitas Audit. Penelitian ini tetap menggunakan Time Budget Pressure sebagai variabel moderasi,karena didasarkan pada penelitian sebelumnya time budget pressure memiliki hasil yang bervariasi dalam menunjukkan pengaruh terhadap variabel dependen, dan pengalaman audit tetap digunakan karena hasil penelitian sebelumnya Time Budget Pressure memperlemah hubungan antara pengalaman audit dan kualitas audit. Sedangkan Nurlita Haerisdia dalam penelitian tentang "The Effect of Independence, Professional Ethics \& Auditor Experience on Audit Quality (2019)" menghasilkan pengalaman audit berpengaruh terhadap kualitas audit. Penelitian lain yang menguji pengaruhnya terhadap kualitas audit seperti independensi, skeptisme, etika auditor sudah banyak diteliti dan menghasilkan pengaruh yang signifikan, dengan demikian dalam penelitian ini tidak meneliti lagi variabel tersebut. Tujuan dan perumusan masalah dalam penelitian ini adalah untuk menganalisis pengaruh $f e e$ audit dan pengalaman audit terhadap kualitas audit, serta menganalisis interaksi kedua variabel independen tersebut (audit fee dan pengalaman audit) terhadap kualitas audit.

\section{TINJAUAN PUSTAKA}

\section{Teori Atribusi}

\section{Teori Atribusi}

Menurut Fritz Heider (1958), teori atribusi menunjukkan tindakan seseorang dalam menjelaskan penyebab perilaku orang lain dan atau dirinya sendiri yang ditentukan dari faktor internal, misal keaslian, karakter, sikap atau faktor seksternal, sebagai contoh tekanan dari situasi tertentu yang akan mempengaruhi perilaku individu.

Berdasarkan teori atribusi dikaitkan dengan penelitian ini dan dihubungkan dengan perilaku auditor dalam menghasilkan kualitas audit, seorang auditor agar menghasilkan audit yang berkualitas dipengaruhi oleh faktor internal yaitu pengalaman audit. Selain itu juga faktor eksternal yaitu audit fee dan time budget pressure. Tekanan waktu (time budget pressure) yang diberikan 
juga akan mempengaruhi perilaku audit, karena dengan waktu yang dibatasi maka auditor cenderung akan menghilangkan urutan dalam prosedur audit dengan pertimbangan mempersingkat waktu audit agar segera menghasilkan laporan audit, tetapi hal ini mengakibatkan berkurangnya kualitas hasil audit.

\section{Kualitas Audit}

Kualitas audit dapat dihasilkan apabila kegiatan audit sudah dilaksanakan sesuai dengan prosedur di dalam pelaksanaan audit. Kualitas audit adalah suatu kemungkinan dalam hal auditor menemukan dan melaporkan adanya pelanggaran dalam sistem akuntansinya (DeAngelo,1981). Deis and Giroux mengemukakan bahwa kualitas audit adalah suatu kemampuan auditor dalam menemukan salah saji yang material dalam laporan keuangan perusahaan klien (Deis and Giroux,1992).

Kertarajasa (2019) hasil nya menyatakan pengalaman dan independensi tidak berpengaruh signifikan terhadap kualitas audit. Faktor eksternal lain yang mempengaruhi kualitas audit adalah Fee Audit dan Time budget pressure. Robertus Aryo Kusuma (2016) dan Valentina (2013) menyatakan bahwa Time Budget Pressure tidak mempengaruhi kualitas audit. Svanberg dan Ohman (2013) meneliti tentang pengaruh time budget pressure dengan kualitas audit tetapi di mediasi oleh budaya etis, hasil menunjukkan bahwa budaya etis dapat memediasi pengaruh antara time budget pressure dengan kualitas audit. Sedangkan Putu Dian Savitri (2018) yang menggunakan time budget pressure sebagai variabel moderasi menyatakan bahwa time budget pressure tidak memoderasi antara pengalaman dan kualitas hasil audit.

Penelitian ini ingin mengetahui beberapa faktor yang mempengaruhi kualitas audit yaitu fee audit dan pengalaman audit, sedangkan time budget pressure adalah sebagai faktor, yang dapat memperkuat atau memperlemah hubungan antar variabel dependen dan independen, tersebut.

\section{Pengembangan Hipotesis}

Fee audit Terhadap Kualitas Audit

Kamil dkk (2018) membuktikan bahwa biaya audit berpengaruh terhadap kualitas audit. Apabila besarnya fee yang didapatkan oleh suditor sesuai dengan apa yang ditetapkan maka akan menghasilkan kualitas audit yang baik. Fee merupakan salah satu motivasi seseorang untuk meningkatkan kualitas kerja. Fee audit yang semakin tinggi, mengakibatkan kualitas audit yang dihasilkan semakin tinggi, karena akan semakin luas pula prosedur audit yang ditempuh, dengan demikian hasil audit akan dapat dipercaya dan akurat,karena auditor akan semakin mendalami proses audit sehingga kemungkinan kejanggalan-kejanggalan yang ada di laporan keuangan klien dapat terdeteksi.

Penelitian luar dilakukan oleh Kam Wah Lai (2019) meneliti tentang Audit report lag, audit fees, and audit quality following an audit firm merger: Evidence from Hongkong memperoleh hasil bahwa pembatasan laporan audit dengan jangka waktu yang pendek, akan meningkatkan fee audit tetapi akan menurunkan kualitas audit. Penelitian Abdul Rahman (2017) yang meneliti hubungan fee audit terhadap kualitas audit di Nigeria memperoleh hasil bahwa fee audit berpengaruh secara signifikan terhadap kualitas audit. Hipotesis yang dikemukakan adalah:

\section{H1: Audit fee berpengaruh positif signifikan terhadap kualitas audit}

\section{Pengalaman Audit Terhadap Kualitas Audit}

Penelitian tentang pengalaman audit terhadap kualitas audit dilakukan Kusuma dan Sukirman (2017) dan Kamil, dkk (2018) yang menemukan bahwa pengalaman kerja berpengaruh secara positif dan signifikan terhadap kualitas hasil audit. Hasil penelitian berbeda diungkapkan oleh Mulyani dan Munthe (2018) bahwa pengalaman kerja tidak berpengaruh terhadap kualitas hasil audit.

Murat dan Ocak (2019) yang meneliti tentang pengaruh auditor pemerintah yang berpengalaman terhadap kualitas audit di Bursa Istambul menghasilkan penelitian yang berlawanan, bahwa semakin auditor tersebut berpengalaman justru membuat kualitas audit mereka menurun, auditor yang berpengalaman dalam sampel penelitian tersebut justru tidak menunjukkan peningkatan kualitas audit, dan mereka menyeselaikan pekerjaan audit dengan sangat lambat, dan tidak mampu mendeteksi discretional accrual secara efektif. Kertarajasa (2019) dalam penelitiannya 
berjudul " The Effect of Competence, Experience, Independence, Due Professional Care and Auditor Integrity on Audit Quality With Auditor Ethics As Moderating Variable" , hasil studi menunjukkan pengalaman dan independensi tidak berpengaruh signifikan terhadap kualitas audit. Hipotesisnya sebagai berikut:

\section{H2: Pengalaman audit berpengaruh positif signifikan terhadap kualitas audit}

\section{Interaksi Time Budget Pressure dan Fee Audit Terhadap Kualitas Audit}

Tekanan terhadap waktu yang diberikan akan memberikan pengaruh terhadap kualitas hasil audit yang dihasilkan. Waktu yang terbatas akan membuat auditor dalam melaksanakan audit tidak berdasar prosedur yang ditetapkan, oleh karena itu auditor seharusnya membuat perencanaan waktu yang tepat dalam melaksanakan audit (Putu Dian Indah Savitri, 2018). Time budget pressure akan sangat mempengaruhi fee auditnya, semakin waktu ditekan maka fee audit juga menyesuaikan.

Robertus Aryo Kusuma (2016) dan Valentina (2013) menyatakan Time Budget Pressure tidak mempengaruhi kualitas audit. Svanberg dan Ohman (2013) meneliti tentang pengaruh time budget pressure dengan kualitas audit tetapi di mediasi oleh budaya etis, hasil menunjukkan bahwa budaya etis sebagai variabel yang memediasi pengaruh antara time budget pressure dengan kualitas hasil audit audit. Hipotesisnya dapat dirumuskan sebagai berikut:

H3: Time budget pressure memoderasi pengaruh antara fee audit terhadap kualitas audit

\section{Interaksi Time Budget Pressure dan Pengalaman Audit Terhadap Kualitas Audit}

Robertus Aryo Kusumo (2016) dan Valentina (2013) memperoleh hasil penelitian bahwa time budget pressure tidak mempengaruhi kualitas audit. Syanberg dan Osman (2013) menyatakan budaya etis dapat memoderasi pengaruh time budget pressure terhadap kualitas audit. Hal ini dapat dijelaskan bahwa, seberapa pun waktu yang diberikan pada auditor, apabila auditor memiliki budaya untuk patuh pada etika profesi maka auditor tetap melaksanakan audit sesuai prosedur audit yang seharusnya tanpa menghilangkan salah satu prosedur, dengan demikian kualitas audit tetap dapat dipertahankan. Sedangkan Putu Dian Savitri (2018) yang menggunakan time budget pressure sebagai variabel moderasi menyatakan time budget pressure tidak memoderasi antara pengalaman dan kualitas hasil audit. Dengan demikian hipotesis yang dikemukakan sebagai berikut:

\section{H4: Time budget pressure memoderasi pengaruh antara pengalaman audit terhadap kualitas} audit

\section{METODE}

Metode yang digunakan adalah survei dengan cara memberikan kuesioner kepada responden penelitian, baik melalui e mail, atau ada yang ditipkan ke KAP yang bersangkutan. Data penelitian berupa data primer yaitu kuesioner yang disebar kepada responden dalam penelitian ini. Populasi dalam penelitian ini auditor pada KAP se Jawa Tengah dan DIY, dengan teknik pengambilan sampel accidental sampling.

\section{HASIL PENELITIAN}

Berdasarkan kriteria accidental sampling maka peneliti berusaha untuk memperoleh kontak dari Kantor Akuntan Publik dari directory iapi 2019, dan mengingat adanya situasi pada saat ini masih diberlakukan adanya pembatasan sosial (PSBB) maka penyebaran kuesioner juga mengalami keterbatasan, yaitu dilakukan dengan melalui e mail, kecuali untuk KAP yang ada di dalam kota Solo, kuesioner masih dapat diantar secara langsung dan itu pun hanya diperbolehkan untuk dititipkan pos keamanan dan diambil kembali apabila sudah diisi. Sehingga dari hasil penyebaran kuesioner berhasil dikumpulkan sebanyak 33 kuesioner dengan rincian KAP di Surakarta ada 17 responden yang mengembalikan kuesioner kemudian untuk KAP yang ada di luar kota Solo melalui e mail terditi dari KAP DIY terdapat 11 kuesioner yang kembali,, KAP di Purwokerto ada 2 sedangkan KAP di Semarang ada 3, sehingga total kuesioner sebanyak 33.

Kuesioner yang terkumpul ditabulasi data untuk kemudian dilakukan pengujian instrument penelitian dan uji asumsi klasik, hasil uji instrument nya valid dan reliabel, sedangkan dari hasil uji asumsi klasik semuanya dinyatakan lolos uji asumsi klasik. Untuk tahap selanjutnya dilakukan uji 
TABEL 1. Hasil Uji Statistik

\begin{tabular}{|c|c|c|c|c|c|c|c|c|c|}
\hline \multicolumn{10}{|c|}{ Model Summary } \\
\hline \multirow[t]{2}{*}{ Model } & \multirow[t]{2}{*}{$\mathrm{R}$} & \multirow{2}{*}{$\begin{array}{c}\mathrm{R} \\
\text { Square }\end{array}$} & \multirow{2}{*}{$\begin{array}{l}\text { Adjusted } \\
\text { R Square }\end{array}$} & \multirow{2}{*}{$\begin{array}{c}\text { Std. Error } \\
\text { of the } \\
\text { Estimate }\end{array}$} & \multicolumn{5}{|c|}{ Change Statistics } \\
\hline & & & & & $\begin{array}{c}\text { R Square } \\
\text { Change }\end{array}$ & F Change & $\mathrm{df1}$ & $\mathrm{df} 2$ & $\begin{array}{c}\text { Sig. F } \\
\text { Change }\end{array}$ \\
\hline 1 &, $949^{a}$ & ,901 & ,895 & 1,42224 & ,901 & 137,103 & 2 & 30 &, 000 \\
\hline
\end{tabular}

TABEL 2. Hasil Uji Regresi

\begin{tabular}{|c|c|c|c|c|c|}
\hline \multirow[t]{2}{*}{ Model } & \multicolumn{2}{|c|}{ Unstandardized Coefficients } & \multirow{2}{*}{$\begin{array}{c}\begin{array}{c}\text { Standardized } \\
\text { Coefficients }\end{array} \\
\text { Beta }\end{array}$} & \multirow[t]{2}{*}{$\mathrm{t}$} & \multirow[t]{2}{*}{ Sig. } \\
\hline & B & Std. Error & & & \\
\hline \multirow{4}{*}{$\begin{array}{l}1 \text { Audit Fee } \\
\text { Pengalaman } \\
\text { Audit }\end{array}$} & $-2,695$ & 2,858 & &,- 943 & 353 \\
\hline & ,741 & ,133 & ,655 & 5,574 & ,000 \\
\hline & ,444 & ,162 & ,322 & 2,740 & ,010 \\
\hline & & & & & \\
\hline
\end{tabular}

a. Dependent Variable: Kualitas Audit

Adapun uji interaksi ditunjukkan dalam tabel berikut:

TABEL 3.Interaksi Audit Fee dan Time Budget Pressure terhadap Kualitas Audit

Coefficients $^{a}$

\begin{tabular}{|c|c|c|c|c|c|c|}
\hline \multirow{2}{*}{\multicolumn{2}{|c|}{ Model }} & \multicolumn{2}{|c|}{ Unstandardized Coefficients } & \multirow{2}{*}{$\begin{array}{c}\text { Standardized } \\
\text { Coefficients } \\
\text { Beta } \\
\end{array}$} & \multirow[t]{2}{*}{$\mathrm{T}$} & \multirow[t]{2}{*}{ Sig. } \\
\hline & & $\mathrm{B}$ & Std. Error & & & \\
\hline \multirow{4}{*}{1} & (Constant) & 42,413 & 20,469 & & 2,072 & ,047 \\
\hline & Audit Fee &,- 740 & ,643 &,- 654 & $-1,150$ & ,260 \\
\hline & Time Budget Pressure &,- 693 &, 571 &,- 566 & $-1,214$ & ,235 \\
\hline & MODERASI1 & ,037 & 017 & 2,143 & 2,177 & ,038 \\
\hline
\end{tabular}

a. Dependent Variable: Kualitas Audit

TABEL 4.Interaksi Pengalaman Audit dan Time Budget Pressure terhadap Kualitas Audit

\begin{tabular}{|c|c|c|c|c|c|}
\hline \multicolumn{6}{|c|}{ Coefficients $^{a}$} \\
\hline \multirow[t]{2}{*}{ Model } & \multicolumn{2}{|c|}{ Unstandardized Coefficients } & Standardized & $\mathrm{T}$ & Sig. \\
\hline & $\mathrm{B}$ & Std. Error & Beta & & \\
\hline $1 \quad$ (Constant) & 76,136 & 25,832 & & 2,947 & ,006 \\
\hline
\end{tabular}



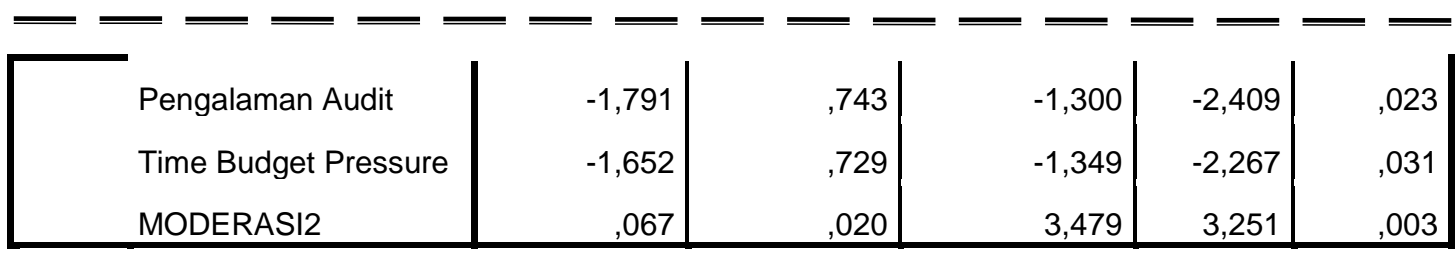

a. Dependent Variable: Kualitas Audit

Dari tabel ditunjukkan bahwa nilai adjusted $\mathrm{R}$ square yang diperoleh adalah sebesar 89,5\% ,artinya pengaruh kedua variabel yaitu fee audit dan pengalaman dalam mempengaruhi kualitas audit sangat besar pengaruhnya yaitu sebesar $889,5 \%$, sedangkan sisanya dipengaruhi oleh variabel lain di luar penelitian ini.

\section{PEMBAHASAN}

\section{Pengaruh Fee Audit terhadap Kualitas Audit}

"Hasil analisis diperoleh nilai t hitung sebesar 5,574 dengan probability value sebesar $0,00<$ 0,05 maka Ho ditolak yang artinya ada pengaruh yang positif dan signifikan audit fee $\left(\mathrm{X}_{1}\right)$ terhadap kualitas audit (Y)." Hasil penelitian ini konsisten dengan hasil penelitian dari Kamil dkk (2018), Chrisdinawidanty dkk (2016), Andriani dan Nursiam (2017), penelitian luar negeri adalah Mulyani dan Munthe (2018), dan Abdul Rahman dkk (2017) yang meneliti di Nigeria menyimpulkan bahwa audit fee memiliki pengaruh yang signifikan dan positif terhadap kualitas audit, hal ini didukung dalam teori atribusi, audit fee merupakan kekuatan eksternal yang berupa motivasi untuk meningkatkan kualitas audit, tujuan dari luasnya prosedur audit adalah untuk mendapatkan bukti yang memadai sehingga mendapatkan hasil yang lebih valid, dengan demikian kualitas hasil audit meningkat.

Sedangkan penelitian ini tidak sejalan dengan penelitian dari Kam Wah Lai (2019) yang meneliti perusahaan merger KAP di Hongkong, yaitu antara Deloitte and Kwan hasilnya menyatakan bahwa setelah merger KAP Deloitte terlihat tidak membebankan fee audit yang tinggi dan juga tidak terlihat penurunan kualitas audit, artinya fee audit tidak berpengaruh secara langsung dengan kualitas auditmya,disamping itu juga dalam penelitian ini meneliti variabel lain yaitu audit report lag, hasilnya juga menyatakan bahwa KAP yang bersansgkutan juga tidak menunjukkan keterlambatan penyampaian audit (audit report lag).

\section{Pengaruh Pengalaman Audit terhadap Kualitas Audit}

Hasil analisis didapat nilai $\mathrm{t}$ hitung 2,740 dengan $p$-value sebesar 0,01 < 0,05 maka Ho ditolak ,artinya ada pengaruh positif dan signifikan pengalaman audit $\left(\mathrm{X}_{2}\right)$ terhadap kualitas audit (Y). Hasil penelitian konsisten dengan Kusuma dan Sukirman (2017) yang mengatakan bahwa pengalaman audit dapat digunakan untuk memperbaiki kinerja pembuatan keputusan dan memperbaiki kualitas audit. Hasil penelitian ini juga didukung oleh hasil penelitian dari Kamil, dkk (2018) yang menyimpulkan bahwa pengalaman audit memiliki pengaruh yang positif dan signifikan terhadap variabel kualitas hasil audit. Hal ini berarti bahwa semakin meningkat pengalaman audit, maka 'kualitas audit juga akan semakin meningkat, sejalan dengan teori atribusi bahwa pengalaman adalah faktor dari dalam internal yang dimiliki auditor selama proses belajarnya.

Tetapi penelitian tidak sejalan dengan Mulyani dan Munthe (2018) yang menyatakan bahwa "pengalaman kerja tidak berpengaruh terhadap kualitas audit," dan tidak sejalan juga dengan Murat dan Ocak (2019) .Hasil kedua penelitian ini dapat disimpulkan bahwa semakin auditor berpengalaman, maka semakin berpengalaman pula dalam memainkan peran auditor untuk menghilangkan salah satu prosedur audit, meskipun akan menghasilkan audit yang tidak berkualitas, hal ini disebabkan adanya faktor etika moral dari masing-masing pribadi auditor, karena meskipun auditor berpengalaman, tetapi apabila etika profesi tidak dijalankan justru dari pengalaman auditor dapat membuat auditor melaksanakan audit dengan tidak sesuai prosedur tetapi hanya memikirkan keuntungan pribadi semata.

\section{Pengaruh Interaksi Time Budget Pressure dan fee audit terhadap Kualitas Audit}

Hasil analisis diperoleh nilai sig sebesar 0,038 < 0,05 artinya hipotesis diterima sehingga "time budget pressure memoderasi pengaruh antara audit fee terhadap kualitas hasil audit." Nilai koefisien regresi sebesar 0,007 positif, artinya moderasi tersebut sifatnya memperkuat pengaruh antara fee audit terhadap time budget pressure. Audit fee yang tinggi akan membuat auditor memiliki motivasi dalam 
meningkatkan kualitas hasil audit, dengan adanya tekanan waktu yang diberikan oleh auditor, justru membuat auditor merasa bertanggung jawab untuk menyelesaikan audit dengan hasil yang berkualitas.

Hal ini sejalan dengan teori atribusi dari Fritz Heider (1958) bahwa terdapat faktor eksternal yang dapat digunakan sebagai sarana memotivasi auditor, dalam hal ini adalah fee audit tersebut, karena fee audit yang tinggi dipengaruhi oleh beberapa faktor, yaitu tingkat kesulitan audit, luasnya prosedur audit dan waktu yang diberikan pada auditor dalam menyelesaikan audit. Adanya tekanan waktu yang meningkat dalam menyelesaikan audit, tetapi apabila fee audit juga meningkat, maka auditor termotivasi untuk menyelesaikan audit sesuai prosedur yang ditetapkan ,dengan demikian diharapkan hasil audit tetap dapat berkualitas.

\section{Pengaruh Interaksi Time Budget Pressure dan Pengalaman Audit terhadap Kualitas Audit}

Hasil analisis diperoleh nilai sig sebesar $0,003<0,05$ artinya hipotesis diterima sehingga 'time budget pressure memoderasi antara pengalaman audit terhadap kualitas audit.' Nilai koefisien regresi sebesar 0,67 positif artinya time budget pressure memperkuat pengaruh antara pengalaman audit terhadap kualitas audit. Pengalaman yang dimiliki oleh auditor menunjukkan semakin banyaknya klien yang diaudit, semakin berpengalaman maka auditor akan semakin menguasai cara melaksanakan audit yang efektif dan efisien, sehingga auditor akan menghasilkan laporan audit yang berkualitas. Dengan adanya tekanan waktu yang diberikan akan memperkuat pengaruh pengalaman auditor dalam menghasilkan audit yang berkualitas, adanya tekanan waktu yang diberikan membuat auditor dapat membuat schedule agar pekerjaan lebih efektif dan efisien sehingga prosedur audit tetap dapat dijalankan tanpa menghilangkan kualitas hasil audit.

Hasil penelitian ini juga sejalan dengan Putu Indah Savitri (2016) yang menyatakan bahwa variabel time budget pressure memoderasi antara pengalaman audit dengan kualitas audit. Tetapi dalam penelitian tersebut time budget pressure sebagai moderasi sifatnya memperlemah, artinya pengalaman auditor yang tinggi tetapi dengan adanya tekanan waktu yang diberikan memungkinkan auditor menghasilkan laporan audit tidak berkualitas karena adanya tekanan waktu tersebut.

\section{PENUTUP}

\section{Kesimpulan}

Hasil penelitian ini adalah audit fee berpengaruh positif dan signifikan terhadap kualitas audit. Hal ini berarti dengan fee yang semakin tinggi maka akan semakin luas pula prosedur audit, dengan begitu hasil audit akan dapat dipercaya dan akurat. Pengalaman audit berpengaruh positif dan signifikan terhadap kualitas audit. .Hal ini berarti pengalaman audit dapat digunakan untuk memperbaiki kinerja pembuatan keputusan dan memperbaiki kualitas audit.. Adanya time budget pressure sebagai variabel moderasi ternyata juga memperkuat pengaruh antara fee aduti dengan kualitas audit dan juga memperkuat pengaruh pengalaman audit terhadap kualitas audit.

Dengan demikian adanya tekanan waktu yang dianggarkan akan mempengaruhi fee auditnya, karena auditor harus menyelesaikan audit dengan waktu yang tersedia sementara prosedur audit tetap harus dijalankan, yang mengakibatkan kualitas audit meningkat. Adapun untuk pengalaman audit, meskipun adanya tekanan waktu, apabila pengalaman auditor semakin banyak, dengan tekanan waktu yang tinggi akan tetap dapat meningkatkan kualitas audit, karena auditor mengetahui cara melaksanakan prosedur audit yang dilakukan.

\section{Saran}

Penelitian ini memiliki keterbatasan, dikarenakan responden yang terkumpul jumlahnya sedikit mengingat dalam situasi pandemic covid 19 mengalami kesulitan dalam penyebaran kuesioner, sehingga kuesioner yang kembali adalah dari hasil pengiriman melalui e mail, dan penyebaran kuesioner bagi responden yang di dalam kota didatangi langsung tetapi hanya sedikit yang mengisi karena karyawan tidak full datang ke kantor, meski demikian responden dalam pengisian kuesioner ini rata-rata adalah sudah berpengalaman dalam mengaudit, hal ini terlihat dari lama waktu bekerja sekitar minimal 3 tahun.

Berdasar keterbatasn penelitian tersebut maka dapat disarankan dalam penelitian selanjutnya dilakukan dalam kondisi yang sudah normal, atau dimungkinkan menambahkan variabel control yatu kondisi pandemic saat ini, dengan demikian penelitisn lebih dapat difokuskan lagi, juga disarankan untuk menambah variabel dari faktor-faktor kualitas audit lain, atau menggunakan variabel intervening. Untuk 
responden juga dapat disarankan untuk memperluas KAP se Indonesia, sehingga hasilnya lebih dapat digeneralisasi dan dapat diperluas dengan membandingkan KAP Big 4 dan Non Big 4.

\section{DAFTAR PUSTAKA}

Abdul Rahman,. Benjamin dan O. H. Olayinka. 2017. "Effect of Audit Fees on Audit Quality: Evidence fro Cement Manufacturing Companies in Nigeria". European Journal of Accounting, Auditing and Finance Research. Vol. 5, No. 1, Januari, p. 6-17.

Agus Widodo M dan Charis Subianto. 2018. Independence, professionalism, professional skepticism. The relation toward the resulted audit quality. www.emeraldinsight.com/2443-4375.htm

Chrisdinawidanty, Zafara N., H. Tugiman dan M. Muslih. 2016. "Pengaruh Etika Auditor dan Fee Audit terhadap Kualitas Audit". e-Proceeding of Management. Vol. 3, No. 3, Desember, p. 34663474 .

Choiriyah, Ririn. 2012. "Pengaruh Time Budget Pressure dan Pengalaman Kerja Auditor terhadap Kualitas Audit Kantor Akuntan Publik di Bali. Jurnal Edisi III. Vol. 1

Kamil, Ihsan, E. Sukarmanto dan M. Maemunah. 2018. "Pengaruh Etika Auditor, Pengalaman Auditor dan Audit Fee terhadap Kualitas Audit". Prosiding Akuntansi. Vol. 4, No. 2, p. 783-790.

Kam-Wah Lai. 2019. Audit report lag, audit fees and audit quality following an audit firm merger: Evidence from Hongkong. Journal of International Accounting, Auditing and Taxation. No 36.

Kertarajasa,Astro Yudha dan Taufiq Marwa.2019.The Effect of Competence,Experience,Independence,Due Professional Care, and Auditor Integrity On Audit Quality With Auditor Ethics As Moderating Variable. http://www.jafas.org

Kusuma dan Sukirman. 2017. "The Effect of Emotional Intelligence and Auditor's Experience on Audit Quality with Independence as A Moderating Variable". Accounting Analysis Journal. Vol. 6, No. 3, p. 370-379.

Mulyani. dan J. O. Munthe. 2018. "Pengaruh Skeptisme Profesional, Pengalaman Kerja, Audit Fee dan Independensi terhadap Kualitas Audit pada KAP di DKI Jakarta". Jurnal Akuntansi Trisakti. Vol. 5, No. 2, September, p. 151-170.

Nurlita, Haeridistia dan A. Fadjarenie. 2019. "The Effect of Independence, Profesional Ethics, and Auditor Experience on Audit Quality". International Journal of Scientific \& Technology Research. Vol. 8, No. 2, Februari, p. 24-27.

Rizky Darmawan S. 2016. "Pengaruh Skeptisme Profesional, Independensi, Integritas, serta Kompetensi Auditor terhadap Kualitas Audit pada Kantor Akuntan Publik di Surabaya”. Akunesa. Vol. 5, No. 1, September, p. 1-24.

Suraida, Ida. 2003. "Pengaruh Etika, Kompetensi, Pengalaman Audit dan Risiko Audit terhadap Skeptisme Profesional Auditor dan Ketepatan Pemberian Opini Akuntan Publik". Jurnal Sosiohumaniora. Vol. 7, No. 3.

Zarefar, Arumega , Andreas dan Atika Zarefar. 2015. The Influence of Ethics, experience and competency toward the quality of auditing with professional auditor skepticism as a Moderating Variable. www.sciencedirect.com 